\title{
OPTIMIZATION OF THE COLLOIDAL PROPERTIES OF DIFFERENT VESICULAR SYSTEMS AIMING TO ENCAPSULATE (-)-EPIGALLOCATECHIN-3-GALLATE
}

\author{
MAHA EL KAYAL ${ }^{1}$, MAHA NASR $^{2 *}$, NAHED MORTADA $^{2}$, SEHAM ELKHESHEN $^{1}$ \\ ${ }^{I}$ Department of Pharmaceutics and Pharmaceutical Technology, Faculty of Pharmaceutical Sciences and Pharmaceutical \\ Industries, Future University in Egypt, Cairo, Egypt \\ ${ }^{2}$ Department of Pharmaceutics and Industrial Pharmacy, Faculty of Pharmacy, Ain Shams University, Egypt
}

*corresponding author: drmahanasr@pharma.asu.edu.eg

Manuscript received: October 2018

\begin{abstract}
The objective of this study was to optimize different vesicular systems containing (-)-epigallocatechin-3-gallate (EGCG); namely penetration enhancer-containing vesicles, ethosomes, transfersomes and transethosomes in order to maximize its therapeutic efficacy. Empty vesicles were prepared using Epikuron 200 and permeation enhancers including polyethylene glycol 400, ethanol, Tween 80 and ethanol/Tween 80 mixture. The colloidal properties of the prepared vesicles were evaluated. Empty vesicles displaying optimum properties were selected for drug loading in order to evaluate their entrapment efficiency. Further optimization of the properties of the drug-loaded vesicles was performed through modification of the conditions of the encapsulation process. Results revealed that decreasing the amount of Epikuron 200 with increasing the percentage of the enhancer reduced the vesicles size and polydispersity index. Loading of vesicles with EGCG markedly increased their size and surface charge. Doubling the volume of hydration medium significantly reduced the size of drug-loaded vesicles while preserving the optimum encapsulation efficiency. Hence, it can be concluded that proper optimization of vesicular properties is necessary in order to maximize the entrapment and consequently the topical therapeutic potential of EGCG.
\end{abstract}

\section{Rezumat}

Scopul acestui studiu a fost optimizarea diferitelor sisteme veziculare conținând (-)-epigallocatechin-3-galat (EGCG) și anume veziculele cu agenți de penetrare, etozomii, transferozomii și transetozomii, pentru a maximiza eficacitatea terapeutică. Veziculele au fost preparate utilizând Epikuron 200 și agenți de îmbunătățire a permeației incluzând polietilen glicol 400, etanol, Tween 80 și amestec etanol/Tween 80 și au fost evaluate proprietăţile lor coloidale. Veziculele goale cu proprietăţi optime au fost selectate pentru încărcarea cu medicamente și s-a determinat eficiența la entrapare. Optimizarea suplimentară a proprietăților veziculelor cu medicament a fost efectuată prin modificarea condițiilor procesului de încapsulare. Rezultatele au arătat că scăderea cantității de Epikuron 200 și creșterea procentului de enhancer a redus dimensiunea veziculelor și indicele de polidispersie. Încărcarea veziculelor cu EGCG a crescut semnificativ mărimea și încărcătura de suprafață. Prin urmare, se poate concluziona că optimizarea adecvată a proprietăților veziculelor este necesară pentru a maximiza entraparea și, în consecință, potenţialul terapeutic topic al EGCG.

Keywords: EGCG, penetration enhancer-containing vesicles, ethosomes, transethosomes

\section{Introduction}

(-)-Epigallocatechin-3-gallate (EGCG) is one of the most promising nutraceuticals extracted from green tea having numerous reported health benefits [28]. In the skin, EGCG exhibits numerous biological effects such as antioxidant, photoprotective, anti-aging and anti-inflammatory $[21,43]$. In different studies, the biological functions of EGCG were proven to be attributed to its structural features, providing it with strong antioxidant and anti-inflammatory properties [52, 114]. However, despite being a promising nutraceutical, its pharmaceutical application is limited because of its chemical instability and low bioavailability [54]. Therefore, several trials have been attempted to maximize the therapeutic potential of EGCG by incorporating it in suitable delivery systems, in order to overcome the limitations encountered with the delivery of EGCG as such [35, 48, 95, 96].

Vesicular systems, especially ultra-deformable vesicles (UDVs) offer numerous clinical advantages for drug delivery [1, 11, 23, 42]. Encapsulation of drugs offers advantages such as decreased drug dose, reduced side effects, increased half-life, high loading capacity and increased intercellular delivery of drugs $[9,14,25,31$, $79,109,115]$. Therefore, vesicles have been widely used as encapsulating carriers for a wide variety of drugs [7, 8, 12, 13, 73, 80, 98]. Another advantage is that they have the ability to guard labile drugs against enzymatic degradation by forming a barrier around drugs which increases resistance to enzymes, digestive juices, and intestinal flora $[4,5,50,82]$. 
Among the most commonly encountered UDVs are penetration enhancer-containing vesicles (PEVs), ethosomes, transfersomes and transethosomes (TEs). Being nontoxic, thermodynamically stable, easily produced, and exhibiting better permeation, these vesicular systems are regarded as a promising delivery system for many drugs [11, 76, 99].

Penetration enhancer-containing vesicles are elastic vesicles prepared from phospholipids (PL) and penetration enhancers (PE) with hydrosoluble glycols at $10 \%$ to $30 \% \mathrm{v} / \mathrm{v}$ concentration that perturbs the PL packing characteristics and fluidizes the vesicle bilayer [75]. Ethosomes are elastic nanovesicles that are made up of PL, water and high concentration of ethanol $(20-45 \%)[68,76,102]$. The interdigitation of high concentration of ethanol exerts a detrimental effect on the vesicular lipid bilayer, increasing its fluidity and rendering it deformable [89]. Transfersomes consist of PL and edge activators (EA) (a single chain surfactant; such as sodium cholate, Spans and Tweens) that enhance the deformability of the vesicular lipid bilayer [27]. Finally, TEs are lipid vesicles based on transfersomes and ethosomes. They contain a high content of ethanol (up to 30\%) together with an EA [11].

The aim of this work was to design and formulate optimized EGCG-loaded vesicular systems to enhance the therapeutic potential of EGCG when applied topically on the skin: PEVs, ethosomes, transfersomes and TEs that essentially consist of PL and different types of permeation enhancers including polyethylene glycol 400 (PEG 400), ethanol (EthOH), Tween 80 (Tw80) and combination of EthOH and Tw80, respectively. Optimization of the colloidal properties of the vesicles (namely particle size, polydispersity index and zeta potential) was carried out through preparing empty vesicular systems and investigating the influence of PL amount and permeation enhancer concentration on these properties. The effect of EGCG loading on the physical properties of the prepared vesicles was also studied, and further optimization trials were performed on the prepared EGCG-loaded vesicular systems in an attempt to attain optimized Nano-EGCG vesicles with optimum physical properties and maximum entrapment efficiency.

\section{Materials and Methods}

(-)-Epigallocatechin-3-gallate was purchased from Bulkactives Company, USA. Epikuron 200 (soybean lecithin containing $92 \%$ phosphatidylcholine) was kindly supplied as a gift from Cargill Inc., Germany. Tween 80 was purchased from Oxford Lab., Mumbay, India. Polyethylene glycol 400 was purchased from Merck-Schuchardt, Hohenbrunn, Germany. Caffeine was purchased from Himedia, Mumbai, India. Methanol and ethanol (HPLC grade) were purchased from SigmaAldrich, Germany.
Preparation of vesicular systems

Different colloidal vesicles were prepared using the thin film hydration technique as described in the literature [32, 47, 61, 90, 107], according to the proportions listed in Tables I to III. Thin film of the dispersion was prepared by means of a rotary evaporator under vacuum (model RII-Buchi, Zurich, Switzerland). Briefly, ethosomes were prepared by dissolving PL in $10 \mathrm{~mL}$ methanol. Methanol was removed at $40^{\circ} \mathrm{C}$ under vacuum, forming a thin lipid film on the inner wall of the round bottom flask. The lipid film was hydrated with fixed volume of different concentrations of hydroethanolic solution, until a vesicular colloidal dispersion was obtained. The colloidal dispersion was rotated at $60 \mathrm{rpm}$ for 1 hour at room temperature, then sonicated using a bath sonicator (Bransonic 3510EDTTH, USA), at $50 \mathrm{cycle} / \mathrm{s}$ for $10 \mathrm{~min}$ at room temperature. Transfersomes and PEVs were prepared applying the same method, where either the EA or PE was dissolved in methanol with PL before evaporation for thin film formation. The thin lipid film was hydrated with double distilled water for 1 hour followed by sonication. In transethosomes, the PL and EA were dissolved in methanol and the hydration of the lipid film was carried out with hydroethanolic solution. For preparation of EGCG-loaded vesicular formulations, the aforementioned procedures were adapted and 25 or $50 \mathrm{mg}$ EGCG was dissolved in methanol before dissolving the PL and the procedure was completed as mentioned previously.

Characterization of Vesicular Systems

Vesicle size, polydispersity (PDI) and zeta potential. Particle size, PDI and zeta potential of the prepared vesicles were determined by dynamic light scattering (DLS) using Zetasizer (model ZEN3600, Malvern Instruments, UK), where $10 \mu \mathrm{L}$ of the vesicular dispersions were diluted with $1 \mathrm{~mL}$ double distilled water before measurements [58, 64].

UPLC assay for the quantitation of EGCG. The quantitation of EGCG in the prepared vesicles was performed using a UPLC method developed and validated in our laboratory [38] as a modification of previously published methods [45, 92]. Briefly, the UPLC system (Agilent 1290 Infinity LC system) equipped with G4204A Quat pump and G4212A photo Diode Array Detector (DAD) was utilized. PURELAB flex water purification system was used. The analytical column ZORBAX RRHD Eclipse Plus C18 (50 mm L $\times 2.1 \mathrm{~mm}$ id, $1.8 \mu \mathrm{m}$ particle size) was utilized for separation. The mobile phase consisted of a mixture of acetic acid (1\% v/v; $\mathrm{pH} 3)$, acetonitrile and water at volume ratio of 13:15:72, which was pumped at a flow rate of $0.5 \mathrm{~mL} / \mathrm{min}$ after filtration through a Millipore $0.22 \mu \mathrm{m}$ filter, followed by sonication. The DAD was set in the range of $210 \mathrm{~nm}$. The sample injection volume was $10 \mu \mathrm{L}$ and a total run time of 5 minutes was applied. 
Entrapment efficiency. The entrapment efficiency $(\% \mathrm{EE})$ of the drug-loaded vesicles was estimated using a previously reported method [24, 62, 97, 108, 111]. An aliquot of $500 \mu \mathrm{L}$ of the vesicular dispersion was placed in the upper chamber of Nanosep centrifuge tubes having ultra-filter with molecular weight cutoff of $100 \mathrm{kDa}$ (OMEGA, Pall Corporation, USA). Nanoseps were centrifuged at $15000 \mathrm{rpm}$ for $30 \mathrm{~min}$ using a high speed refrigerated centrifuge at $-5^{\circ} \mathrm{C}$ (Sigma 3-30KS, Germany). The filtrate containing the free EGCG was collected from the lower chamber, diluted and analysed using the previously described UPLC method. The encapsulation or entrapment efficiency $(\% \mathrm{EE})$ was determined relative to the originally added drug amount, according to the following equation:

$$
\% \mathrm{EE}=(\mathrm{A} 1-\mathrm{A} 2) \times 100 / \mathrm{A} 1, \quad \text { Eq. } 1)
$$

where, $\mathrm{A} 1=$ Total EGCG added, $\mathrm{A} 2=$ Free EGCG, $(\mathrm{A} 1$ - A2) = represents the amount of EGCG entrapped in the vesicles.

Statistical analysis

All results are expressed as mean \pm standard deviation (SD) of three independent replicates of the experiments. The effect of different formulation variables on the vesicular characteristics was tested for significance applying one-way ANOVA followed by Tukey posttest using GraphPad InStat 3.1 software. Values of $\mathrm{p}>0.05$ were considered not significant.

\section{Results and Discussion}

\section{Preliminary screening}

The selection of enhancers used in the preparation of the vesicular systems in the present study was made based on preliminary work that was carried out on various enhancers of different properties (Data not shown). PEG 400, being a safe biocompatible penetration enhancer was selected for the preparation of PEVs. It works by reducing the interfacial tension between water and hydrophobic drugs. It was previously reported that PEG 400 strongly interacts with the inter-lamellar water layers and the polar regions of PL, improving vesicular bilayer fluidity and also reducing the stratum corneum (SC) barrier function transiently, thus creating an easier pathway for the highly fluidized vesicles [26, 67]. Ethanol is also known as an efficient permeation enhancer that has been added in ethosomes to render them elastic and malleable. It has the ability to interact with the polar head group region of the lipid molecules, resulting in the reduction of the melting point of the SC lipid, and increasing lipid fluidity and permeability of the cell membrane. In addition, the high flexibility of vesicular membranes rendered by the addition of EthOH permits the squeezing of the elastic ethosomes through the pores of SC, which are much smaller than vesicle diameters. Therefore, ethosomes are very efficient in delivering substances to the skin in the terms of quantity and depth $[103,106]$.
Tween 80 , being a single chain surfactant, destabilizes lipid bilayer of the vesicles, increasing the deformability of bilayer in transfersomes through decreasing the interfacial tension [55]. Transfersomes can cross the skin layers either while maintaining their intact structure or after fusing and mixing with skin lipids [39], where they can easily change their shape in response to mechanical stress [40]. As a result, transfersomes can easily squeeze through channels with one-tenth of the vesicles diameter and cross the SC [11]. Therefore, aiming to formulate EGCG-loaded vesicular systems with acceptable physical properties (particle size, PDI and zeta potential) as well as optimized entrapment efficiency to enhance their topical application, PEG 400, EthOH and Tw80 were selected for preparing PEVs, ethosomes and transfersomes, respectively.

Optimization of the colloidal properties of empty vesicular systems

Optimization of formulation composition is an essential step towards producing stable particles, with acceptable performance as a drug delivery system. The nature and ratio of the vesicle constituents have a great effect on their physicochemical properties [16]. Therefore, it was important to study the effect of different formulation factors adapted in our laboratory on particle size, PDI and charges on the prepared vesicular systems. Penetration enhancer-containing vesicles (PEVs)

PEVs were prepared using varying amounts of PL and PEG 400 as presented in Table I. All formulae exhibited relatively large particle size (ranging from $542.6 \mathrm{~nm}$ to $6230 \mathrm{~nm}$ ). This can be attributed to the hydrophilic nature of PEG 400 which increases vesicles hydration. Immobilization of water molecules in the presence of PEG 400 leads to a consequent modification of the bilayer swelling condition producing larger vesicle size with wider range of distribution. Similar results were reported in previous studies [26, 74].

On investigating the effect of PL amounts on the characteristics of PEVs, it was observed that the progressive increase of the amount of PL (300 mg, $600 \mathrm{mg}$ and $900 \mathrm{mg}$ ) significantly increased the vesicles particle size which was more pronounced in presence of 5\% PEG rather than 10\% PEG $(\mathrm{P}<0.05)$. This growth in vesicles size could be attributed to the predominant effect of PL amount on the formation, growth and closure of intermediate bilayered PL fragments [6]. Furthermore, it is expected that increasing the amount of PL involved in vesicular formation provides the vesicular membrane with higher rigidity, thereby strengthens the bilayer structures and diminishes bilayer micro fluidity; a situation that would interfere with the size reduction during sonication. This was in agreement with the results obtained by many authors while studying the encapsulation of various drugs $[18,46,65,66,72,85,93,117]$. 
Effect of composition on the colloidal properties of empty PEVs (mean $\pm \mathrm{SD}, \mathrm{n}=3$ )

\begin{tabular}{|c|c|c|c|c|c|c|}
\hline \multirow{3}{*}{$\begin{array}{c}\text { Formula } \\
\text { Code }\end{array}$} & \multicolumn{3}{|c|}{ Composition } & \multirow[t]{3}{*}{ Particle size (nm) } & \multirow[t]{3}{*}{ PDI } & \multirow[t]{3}{*}{ Zeta Potential $(\mathrm{mV})$} \\
\hline & \multirow{2}{*}{$\begin{array}{c}\text { PL } \\
(\mathrm{mg})\end{array}$} & \multicolumn{2}{|c|}{ Hydration medium } & & & \\
\hline & & PEG $400(\%, \mathrm{v} / \mathrm{v})$ & $\mathrm{H}_{2} \mathrm{O}(\%, \mathrm{v} / \mathrm{v})$ & & & \\
\hline P1 & 300 & 5 & 95 & $900.3 \pm 19.23$ & $0.55 \pm 0.10$ & $-4.04 \pm 0.18$ \\
\hline $\mathrm{P} 2$ & 300 & 10 & 90 & $542.6 \pm 19.09$ & $0.54 \pm 0.04$ & $-3.03 \pm 0.06$ \\
\hline P3 & 600 & 5 & 95 & $1065 \pm 14.14$ & $0.56 \pm 0.002$ & $-3.47 \pm 0.17$ \\
\hline $\mathrm{P} 4$ & 600 & 10 & 90 & $765 \pm 6.58$ & $0.61 \pm 0.02$ & $-5.59 \pm 1.92$ \\
\hline $\mathrm{P} 5$ & 900 & 5 & 95 & $6230 \pm 111.9$ & $1.00 \pm 0$ & $-2.27 \pm 0.10$ \\
\hline P6 & 900 & 10 & 90 & $901 \pm 84.64$ & $0.64 \pm 0.02$ & $-3.32 \pm 2.87$ \\
\hline
\end{tabular}

With regard to PDI values, they increased with increasing the amount of PL as well. This could be attributed to the formation of thinner film at lower PL content $(300 \mathrm{mg})$ during the evaporation of methanol, as well as the creation of low-viscosity dispersion after hydration, which enhanced the efficiency of the ultrasonic power to subdivide the particles to smaller size with narrower distribution range. However as a general observation, all the prepared PEVs had PDI values above 0.5 (ranging from 0.54 to 1$)$. In other words, all the formulae exhibited wide non-homogenous distribution.

The zeta potential values of all the prepared PEVs were relatively low, ranging from -2.27 to $-5.59 \mathrm{mV}$, as displayed in Table I. Despite the variations in zeta potential values, the difference between them was insignificant $(p \geq 0.05)$. The low values of zeta potential of the prepared PEVs could be ascribed to the inverse relationship existing between particle size and zeta potential [77] as a result of surface area reduction. Moreover, the low values of zeta potential of the prepared PEVs can also be attributed to the presence of PEG 400 which was thought to form a compact conformation cloud (mushroom cloud) around the vesicles, shielding the negative charge carried by the PL vesicles themselves [113].

Regarding the effect of the concentration of PEG 400 in the hydration medium on the colloidal properties of the PEVs, it was observed that increasing PEG 400 concentration from $5 \%$ to $10 \%$ significantly reduced particle size ( $p<0.05)$. PEG 400 at higher concentration is thought to exert more perturbation effect on the PL packing characteristics in the bilayer (due to the extensive interaction with and immobilization of water molecules) thereby enhances the bilayer fluidity and causes more size reduction upon sonication. Increasing PEG 400 concentration caused a significant reduction ( $\mathrm{p}<0.05$ ) on PDI values of PEVs containing $900 \mathrm{mg}$ of PL only. Regarding the effect of increasing the concentration of PEG 400 on zeta potential, it was insignificant as the shielding effect of PEG on vesicles' charges was pronounced even at low concentration as reflected by the low values presented by all formulae. Ethosomes

The effect of two factors, namely the PL amount and EthOH concentration on the particle size, PDI and zeta potential of vesicles was tested (Table II).
Increasing the amount of PL from $200 \mathrm{mg}$ to $400 \mathrm{mg}$ and $600 \mathrm{mg}$ significantly increased the particle size of ethosomes $(\mathrm{p}<0.05)$, as a result of increasing the incorporated amount of PL in vesicles bilayer during formulation and the consequent increase in rigidity and resistance to size reduction as encountered with PEVs. Decreasing the amount of the PL not only produced vesicles of smaller size but also produced homogenous vesicular distribution (PDI ranged from 0.2 to 0.51 for vesicles containing $200 \mathrm{mg}$ of PL) which was justified by the efficient effect of the sonication power as a result of the thin film formation during evaporation of methanol and the low viscosity of the dispersion after hydration and during sonication. The results are in accordance with the data reported by Zhaowu et al. [117].

Zeta potential of all the prepared ethosomal formulae exhibited negative values, ranging from -1.13 to $-17.1 \mathrm{mV}$, which can be attributed to the nature of EthOH, being a negative charge provider to the surface of ethosomes [3, 30]. A possible mechanism through which EthOH can impart the negative charge is that $\mathrm{EthOH}$ (through its dipoles) can increase the degree of polarization of the carbonyl group in PLs. In addition, EthOH can provide a nucleophile $\left(-\mathrm{OC}_{2} \mathrm{H}_{5}\right)$ to attach the carbonyl carbon creating a negative charge on the oxygen atom, as explained by Connors et al. [29], thus imparting negative zeta potential to the vesicles. Increasing PL amount significantly reduced the zeta potential ( $p<0.05$ ), where $200 \mathrm{mg}$ PLcontaining ethosomes exhibited zeta potential values ranging from -9.43 to $-17.1 \mathrm{mV}$ while $600 \mathrm{mg}$ PLcontaining ethosomes exhibited reduced zeta potential values ranging from -1.13 to $-5.59 \mathrm{mV}$. The decrease in zeta potential of the prepared vesicles with increasing PL amount could be ascribed to the increase in particle size and hence reduction of surface area carrying the charges as also encountered with PEVs. These findings were in accordance with the results obtained by Nascimento et al. where an increase in zeta potential of the prepared vesicles was accompanied by a decrease in vesicle size [78].

Inspecting the effect of EthOH on the colloidal characteristics of ethosomes revealed that it affects the particle size of ethosomes oppositely to the PL amount, where increasing the concentration gradually 
FARMACIA, 2020, Vol. 68, 1

from $10 \%$ to $40 \%$ while keeping PL amount constant caused significant reduction in particle size $(\mathrm{p}<0.05)$. In accordance with other authors, the decrease in vesicles size might be due to the fact that at higher EthOH concentration, the vesicle membrane thickness is reduced considerably, probably as a result of the formation of a phase with interpenetrating hydrocarbon chain of EthOH in the vesicular lipid bilayers [86]. The reduction of the membrane thickness allows easier and faster vesicle subdivision under constant sonication period and hence smaller particle size is obtained.

Effect of composition on the colloidal properties of empty ethosomes (mean $+\mathrm{SD}, \mathrm{n}=3$ )

\begin{tabular}{|c|c|c|c|c|c|c|}
\hline \multirow{3}{*}{$\begin{array}{l}\text { Formula } \\
\text { Code }\end{array}$} & \multicolumn{3}{|c|}{ Composition } & \multirow[t]{3}{*}{ Particle size (nm) } & \multirow[t]{3}{*}{ PDI } & \multirow[t]{3}{*}{ Zeta Potential (mV) } \\
\hline & \multirow[t]{2}{*}{ PL (mg) } & \multicolumn{2}{|c|}{ Hydration medium } & & & \\
\hline & & EthOH $(\%, v / v)$ & $\mathrm{H}_{2} \mathrm{O}(\%, \mathrm{v} / \mathrm{v})$ & & & \\
\hline E1 & 200 & 10 & 90 & $607.7 \pm 4.88$ & $0.51 \pm 0.04$ & $-17.1 \pm 0.61$ \\
\hline E2 & 400 & 10 & 90 & $2448 \pm 89.1$ & $0.94 \pm 0.09$ & $-7.34 \pm 0.53$ \\
\hline E3 & 600 & 10 & 90 & $5426 \pm 464.6$ & $0.61 \pm 0.15$ & $-5.59 \pm 1.2$ \\
\hline $\mathrm{E} 4$ & 200 & 20 & 80 & $475 \pm 0.64$ & $0.47 \pm 0.02$ & $-10.1 \pm 1.13$ \\
\hline E5 & 400 & 20 & 80 & $1082 \pm 82.02$ & $0.87 \pm 0.19$ & $-4.18 \pm 0.18$ \\
\hline E6 & 600 & 20 & 80 & $4326 \pm 813.2$ & $0.78 \pm 0.03$ & $-1.13 \pm 0.72$ \\
\hline E7 & 200 & 30 & 70 & $294.9 \pm 2.62$ & $0.26 \pm 0.01$ & $-13.7 \pm 0.14$ \\
\hline E8 & 400 & 30 & 70 & $616.85 \pm 0.14$ & $0.37 \pm 0.14$ & $-3.98 \pm 0.48$ \\
\hline E9 & 600 & 30 & 70 & $1619 \pm 97.58$ & $0.82 \pm 0.01$ & $-2.64 \pm 0.18$ \\
\hline E10 & 200 & 40 & 60 & $241.3 \pm 2.33$ & $0.20 \pm 0.02$ & $-9.43 \pm 0.59$ \\
\hline E11 & 400 & 40 & 60 & $461.8 \pm 7.99$ & $0.55 \pm 0.01$ & $-5.27 \pm 0.06$ \\
\hline E12 & 600 & 40 & 60 & $725.5 \pm 4.5$ & $0.64 \pm 0.11$ & $-1.54 \pm 0.09$ \\
\hline
\end{tabular}

The PDI values of $200 \mathrm{mg}$ PL-containing ethosomes were significantly reduced as the EthOH concentration increased ( $\mathrm{p}<0.05$ ). In $400 \mathrm{mg}$ PL-containing formulae, PDI values were insignificantly reduced $(p>0.05)$, with the values being higher than those observed with $200 \mathrm{mg}$ PL-containing ethosomes. In $600 \mathrm{mg}$ PLcontaining formulae, PDI values were all above 0.5 (from 0.614 to 0.823 ), indicating a non-homogenous distribution of the ethosomes in the dispersion media which is probably attributed to the inability of EthOH to decrease PL membrane thickness at such high PL level in the membrane.

Regarding zeta potential, it was observed that however EthOH is negative charge imparting agent, increasing EthOH concentration above $10 \%$ significantly reduced the zeta potential of the prepared ethosomes $(\mathrm{P}<0.05)$. It was previously reported that $\mathrm{EthOH}$ was responsible for changing the orientation of PL polar head in the bilayer that may reduce the electrical double layer thickness around the vesicle due to repulsion which is reflected on changes in the electrical charge on the vesicle surface [110]. Furthermore, Labhasetwar et al. stated that the change in the lipid bilayer could influence the electrical layers around the vesicles and accordingly the zeta potential [63].

Transfersomes

Transfersomes were prepared using $\mathrm{Tw}_{80}$ as edge activator. The effect of varying PL: $\mathrm{Tw}_{80}$ ratio (\% $\mathrm{w} / \mathrm{w})$ in the formation of the vesicles, in addition to the effect of increasing total PL + Tw$_{80}$ content, while keeping their ratio constant, on the particle size, PDI and zeta potential of the prepared transfersomal dispersions was studied (Table III).

Table III

Effect of composition on the colloidal properties of empty transfersomes (mean $\pm \mathrm{SD}, \mathrm{n}=3$ )

\begin{tabular}{|c|c|c|c|c|c|c|}
\hline \multirow{3}{*}{$\begin{array}{l}\text { Formula } \\
\text { Code }\end{array}$} & \multicolumn{3}{|c|}{ Composition } & \multirow{3}{*}{$\begin{array}{l}\text { Particle size } \\
(\mathrm{nm})\end{array}$} & \multirow[t]{3}{*}{ PDI } & \multirow[t]{3}{*}{ Zeta Potential (mV) } \\
\hline & \multirow[t]{2}{*}{$\begin{array}{c}\text { PL:Tw80 ratio } \\
(\%, w / w)\end{array}$} & \multirow[t]{2}{*}{$\begin{array}{c}\text { Total PL+Tw80 } \\
\text { content }(\mathrm{mg})\end{array}$} & $\begin{array}{l}\text { Hydration } \\
\text { medium }\end{array}$ & & & \\
\hline & & & $\mathrm{H}_{2} \mathrm{O}(\%, \mathrm{v} / \mathrm{v})$ & & & \\
\hline $\mathrm{T} 1$ & \multirow[t]{3}{*}{$90: 10$} & 200 & 100 & $741.5 \pm 7.99$ & $0.63 \pm 0.01$ & $-4.57 \pm 0.03$ \\
\hline $\mathrm{T} 2$ & & 400 & 100 & $610.6 \pm 52.89$ & $0.55 \pm 0.01$ & $-3.05 \pm 0.29$ \\
\hline T3 & & 600 & 100 & $157.4 \pm 4.031$ & $0.59 \pm 0.01$ & $-2.13 \pm 0.02$ \\
\hline $\mathrm{T} 4$ & \multirow[t]{3}{*}{$85: 15$} & 200 & 100 & $617.3 \pm 44.69$ & $0.65 \pm 0.02$ & $-1.76 \pm 0.29$ \\
\hline $\mathrm{T5}$ & & 400 & 100 & $593.1 \pm 21.92$ & $0.56 \pm 0.002$ & $-1.58 \pm 0.52$ \\
\hline T6 & & 600 & 100 & $153.4 \pm 1.909$ & $0.51 \pm 0.09$ & $-0.266 \pm 0.1$ \\
\hline $\mathrm{T} 7$ & \multirow[t]{3}{*}{$80: 20$} & 200 & 100 & $580 \pm 44.69$ & $0.55 \pm 0.02$ & $-3.53 \pm 0.35$ \\
\hline $\mathrm{T} 8$ & & 400 & 100 & $552.5 \pm 4.03$ & $0.67 \pm 0.04$ & $-2.94 \pm 0.49$ \\
\hline T9 & & 600 & 100 & $516.2 \pm 82.08$ & $0.62 \pm 0.02$ & $-3.22 \pm 0.61$ \\
\hline
\end{tabular}


The progressive increase of $\mathrm{Tw}_{80}$ content in the total PL/Tw 80 amount (90:10, 85:15 and 80:20 PL:Tw 80 ratios) reduced the particle size of all formulae insignificantly, except for the formula prepared with 80:20 PL:Tw80 ratios with total amount of $600 \mathrm{mg}$ of both components which showed significant increase in particle size. The reduction in particle size of the prepared transfersomes may be attributed to the destabilization effect of Tw80 on the lipid bilayers of transfersomes which increases flexibility [33], leading to the formation of vesicles of smaller sizes [41]. The reduction in particle size upon increasing $\mathrm{Tw}_{80}$ concentration was in agreement with the results reported by Irfan et al. [53] and Nava et al. [81]. The unexpected increase in particle size in the formula prepared with 80:20 PL:Tw80 ratios with total amount of $600 \mathrm{mg}$ may be attributed to the fact that the combined effect of high total PL+Tw $w_{80}$ content $(600 \mathrm{mg})$ and the high viscosity imparted by the presence of excess $\mathrm{Tw}_{80}$ in the dispersion medium opposed its main effect in increasing the elasticity of the vesicles and the consequent size reduction during sonication. Regarding the PDI, it was observed that there was a statistically insignificant difference among the prepared formulae (T1 - T9) (P > 0.05). The PDI value of all the prepared formulae ranged from 0.51 to 0.67 , which were relatively high (above 0.5 ). In other words, all the prepared transfersomal dispersions exhibited heterogeneous (wide size range) distribution.

As listed in Table III, the zeta potential of transfersomal vesicles ranged from -1.58 to $-4.57 \mathrm{mV}$. Despite the variations, it can be noticed that all the prepared formulae exhibited experimentally small values of zeta potential (insignificant among all tested formulae $p>0.05$ ). The reason behind the negative zeta potential of the prepared transfersomal dispersions may be solely attributed to the zwitter-ion nature of the PL [34, 100]. The relation between increasing $\mathrm{Tw}_{80}$ concentration and reduction in zeta potential may be attributed to the fact that $\mathrm{Tw}_{80}$ molecules are amphiphilic molecules that prefer deposition at the particles surfaces which lead to shielding the surface charges being non-ionic surfactant. The shielding effect of $\mathrm{Tw}_{80}$ on surfaces charges was previously reported with both polymeric nanoparticles $[10,112]$ as well as vesicular systems $[17,52]$.

In contrary to the effect of increasing the PL content which significantly increased the particle size of both PEVs and ethosomes, the effect of increasing the total PL+Tw $w_{80}$ content was the reduction of the particle size of transfersomes. This reduction was highly significant $(\mathrm{p}<0.05)$ in transferosomes prepared with 90:10 and 85:15 PL:Tw80 ratios. The effect of total PL+Tw80 content was less pronounced when PL:Tw80 ratio was above $85: 15$ ( $p>0.05)$. The decrease in vesicle size associated with increasing PL+Tw80 content can be explained based on the assumption that increasing total PL+Tw80 content gradually from $200 \mathrm{mg}$ to $600 \mathrm{mg}$ created crowding in the dispersion media. As a result, the average distance between neighboring vesicles and excess Tw80 molecules that are uninvolved in vesicle formation is reduced. The increase in $\mathrm{Tw}_{80}$ concentration per unit volume of the dispersion medium is expected to increase the efficiency of Tw80 as a surfactant to reduce surface free energy on vesicles' surfaces, accompanied by population of small size. Therefore, $\mathrm{Tw}_{80}$ initiated higher vesicles sub-deviation and stabilization by adsorption/re-adsorption of $\mathrm{Tw}_{80}$ on vesicular surface, due to the presence of hydrophobic methylene groups in the long acetyl side chain of $\mathrm{Tw}_{80}$ that tends to adsorb more strongly and form a thicker layer on vesicles' surface. Similar surface adsorption was encountered with $\mathrm{Tw}_{80}$ and gold nanoparticles [116].

On the other hand, insignificant changes in the PDI were observed upon increasing total PL+Tw80 content. All transfersomal dispersions exhibited wide size distribution, ranging from 0.506 to 0.668 .

Increasing the total PL+Tw $w_{80}$ content gradually from $200 \mathrm{mg}$ to $600 \mathrm{mg}$ significantly reduced zeta potential of transfersomes in 90:10 and 85:15 PL:Tw8 ratios ( $p<0.05)$. However in 80:20 PL:Tw $w_{80}$ formula, zeta potential was insignificantly reduced upon increasing PL+Tw80 content $(\mathrm{p}>0.05)$. Despite the statistical significance, the experimental values of the obtained zeta potential were very low ranging from -0.266 to -4.57 that showed insignificant difference when analysed collectively.

Transethosomes (TEs)

Two transethosomal formulae were prepared, namely TE4 and TE6 based on selected transfersomal formulae T4 and T6 (Table IV). It was observed that the addition of ethanol to the hydration medium of transethosomes prepared with $600 \mathrm{mg}$ total PL+Tw80 significantly $(p<0.05)$ increased the particle size of TE6 compared to T6. The formula exhibited PDI value of 0.51 and zeta potential of $-1.43 \mathrm{mV}$. The increase in particle size accompanying the addition of EthOH to this transfersomal dispersion could be ascribed to the gel forming potential of PL-EthOH-aqueous mixtures at high EthOH concentration and the induced interdigitation of PL bilayers by EthOH [69, 84]. Moreover, Komatsu et al. [60] attributed the increase in liposomes' size under the effect of EthOH to the liposomal aggregation and fusion-induced by EthOH incorporation. The effect can also be attributed to the reduction in the degree of hydration of PL molecules as a result of association between the added alcohol and water molecules through hydrogen bond formation. The reduction of PL hydration causes aggregation due to the disappearance of the highly bounded water molecules on the bilayer surfaces, resulting in increased vesicles size. This came in accordance with the results obtained by Bseiso et al. [22], Kõiv et al. [59] and Shamma et al. [94]. 
Table IV

Effect of composition on the colloidal properties of empty transethosomes in comparison to transfersomes

\begin{tabular}{|c|c|c|c|c|c|c|c|}
\hline \multirow{3}{*}{$\begin{array}{l}\text { Formula } \\
\text { Code }\end{array}$} & \multicolumn{4}{|c|}{ Composition } & \multirow{3}{*}{$\begin{array}{l}\text { Particle size } \\
(\mathrm{nm})\end{array}$} & \multirow[t]{3}{*}{ PDI } & \multirow{3}{*}{$\begin{array}{l}\text { Zeta Potential } \\
(\mathrm{mV})\end{array}$} \\
\hline & \multirow{2}{*}{$\begin{array}{c}\text { PL: Tw80 ratio } \\
(\%, w / w)\end{array}$} & \multirow{2}{*}{$\begin{array}{c}\text { Total PL+Tw80 } \\
\text { content (mg) }\end{array}$} & \multicolumn{2}{|c|}{ Hydration medium } & & & \\
\hline & & & $\begin{array}{c}\text { EthOH } \\
(\%, \mathrm{v} / \mathrm{v})\end{array}$ & $\begin{array}{c}\mathrm{H} 2 \mathrm{O} \\
(\%, \mathrm{v} / \mathrm{v})\end{array}$ & & & \\
\hline $\mathrm{T} 4$ & $85: 15$ & 200 & 0 & 100 & $617.3 \pm 44.69$ & $0.65 \pm 0.02$ & $-1.76 \pm 0.29$ \\
\hline TE4 & $85: 15$ & 200 & 40 & 60 & $267.6 \pm 2.83$ & $0.44 \pm 0.01$ & $-0.56 \pm 0.02$ \\
\hline T6 & $85: 15$ & 600 & 0 & 100 & $153.4 \pm 1.909$ & $0.51 \pm 0.09$ & $-0.266 \pm 0.1$ \\
\hline TE6 & $85: 15$ & 600 & 40 & 60 & $650.8 \pm 35.85$ & $0.51 \pm 0.04$ & $-1.43 \pm 0.30$ \\
\hline
\end{tabular}

On the contrary, upon inspecting the properties of formula TE4 prepared using lower amount of total PL+Tw $w_{80}(200 \mathrm{mg})$, better physicochemical properties were achieved (Table IV). The particle size and PDI values of TE4 significantly decreased upon EthOH addition ( $\mathrm{p}<0.05$ ) which could be attributed to the dual fluidizing effect posed by both $\mathrm{Tw}_{80}$ and EthOH in presence of low amount of PL, in which the former ( $\mathrm{Tw}_{80}$ ) causes destabilization of the lipid bilayers of TEs, hence increases the flexibility of these vesicles, while the latter $(\mathrm{EthOH})$ causes membrane thinning, together leading to decreased particle size in the presence of low PL amount.

The difference in the effect of EthOH on the size and homogeneity of TEs between the two formulae, TE4 and TE6, could be attributed to the level of PL per the two formulae. It could be assumed that alcohol was not able to augment the edge activating action of $\mathrm{Tw}_{80}$ in presence of high concentration of PL in TE6 as it interfered with the required high level of hydration in presence of $600 \mathrm{mg}$ of total PL+Tw 80 amount compared to the low total amount of PL+Tw80 of $200 \mathrm{mg}$ in TE4.

EGCG loading into the selected vesicular systems Effect of EGCG loading on the particle size, PDI and zeta potential of vesicular systems. Two formulae, exhibiting the optimum colloidal properties from each of the vesicular systems (ethosomes; E7 \& E10, transfersomes; T3 \& T6, PEVs; P2 \& P4 and TEs; TE4
\& TE6) were selected for drug loading. Depending on the results obtained from a preliminary study and referring to the work previously published by Fang et al. [43], a $50 \mathrm{mg}$ dose of EGCG was selected to be incorporated in each formula and the effect of EGCG loading on the physical properties of vesicular systems was studied. Results are graphically illustrated in Figure 1.

As a general observation, loading the vesicles with EGCG increased particle size to different extents. Increasing particle size with EGCG loading was more significant in ethosomes $(\mathrm{p}<0.001)$, while the lowest effect was observed with PEVs ( $p>0.05)$. The concomitant increase in PDI values of vesicular dispersions upon EGCG loading is in consistence with particle size enlargement; whereas the particle size increased the vesicular dispersion became more heterogeneous. The size enlargement and the increase in PDI values can be attributed to the bicyclic structure of EGCG, which was previously reported by Sun et al. [101] to cause enlargement in liposomes curvature radius and lamellarity upon its incorporation. Regarding zeta potential, the increased negativity observed in ethosomes, transfersomes and TEs upon EGCG incorporation is ascribed to the inherent negative charge of EGCG resulting from the galloyl moiety of the drug at the 3-position, which has three hydroxyl groups, providing a source of negative charge in aqueous solutions [43].

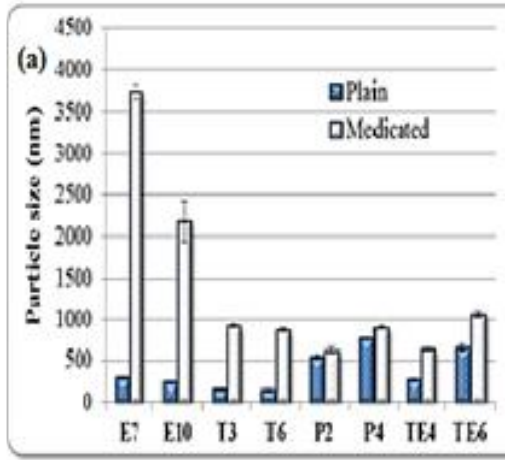

Figure 1.
Effect of EGCG loading on the particle size (a), PDI (b), an
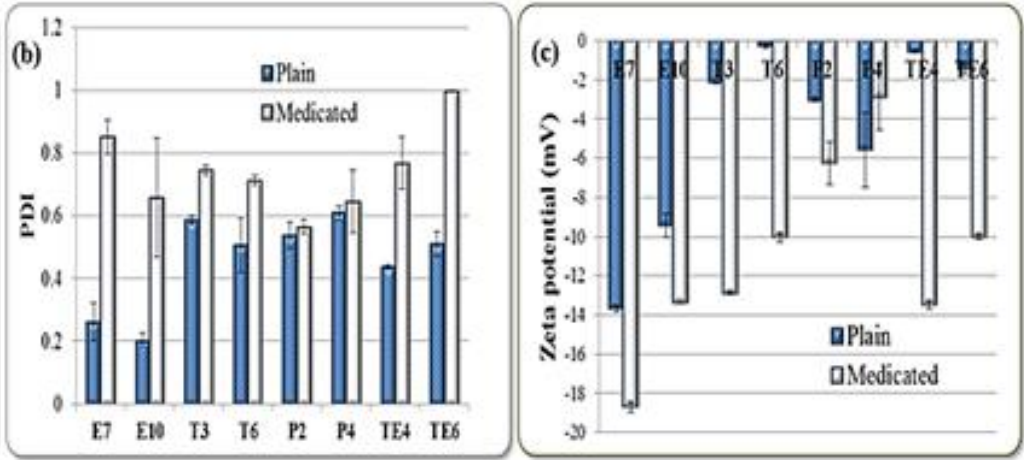

Effect of EGCG loading on the particle size (a), PDI (b), and zeta potential (c) of different vesicular systems 
Effect of decreasing EGCG loaded dose on the particle size, PDI, zeta potential and entrapment efficiency of vesicular systems. Aiming to reduce the particle size and increase the formulae homogeneity after loading with the drug, a study was carried out to investigate the effect of decreasing the EGCG loaded dose on the colloidal properties as well as the \%EE of the prepared vesicles. Vesicles which showed smaller particle sizes upon loading with $50 \mathrm{mg}$ EGCG, namely: P2", E10", T6" and TE4" were selected for loading with half dose (25 mg) of EGCG (Figure 2).
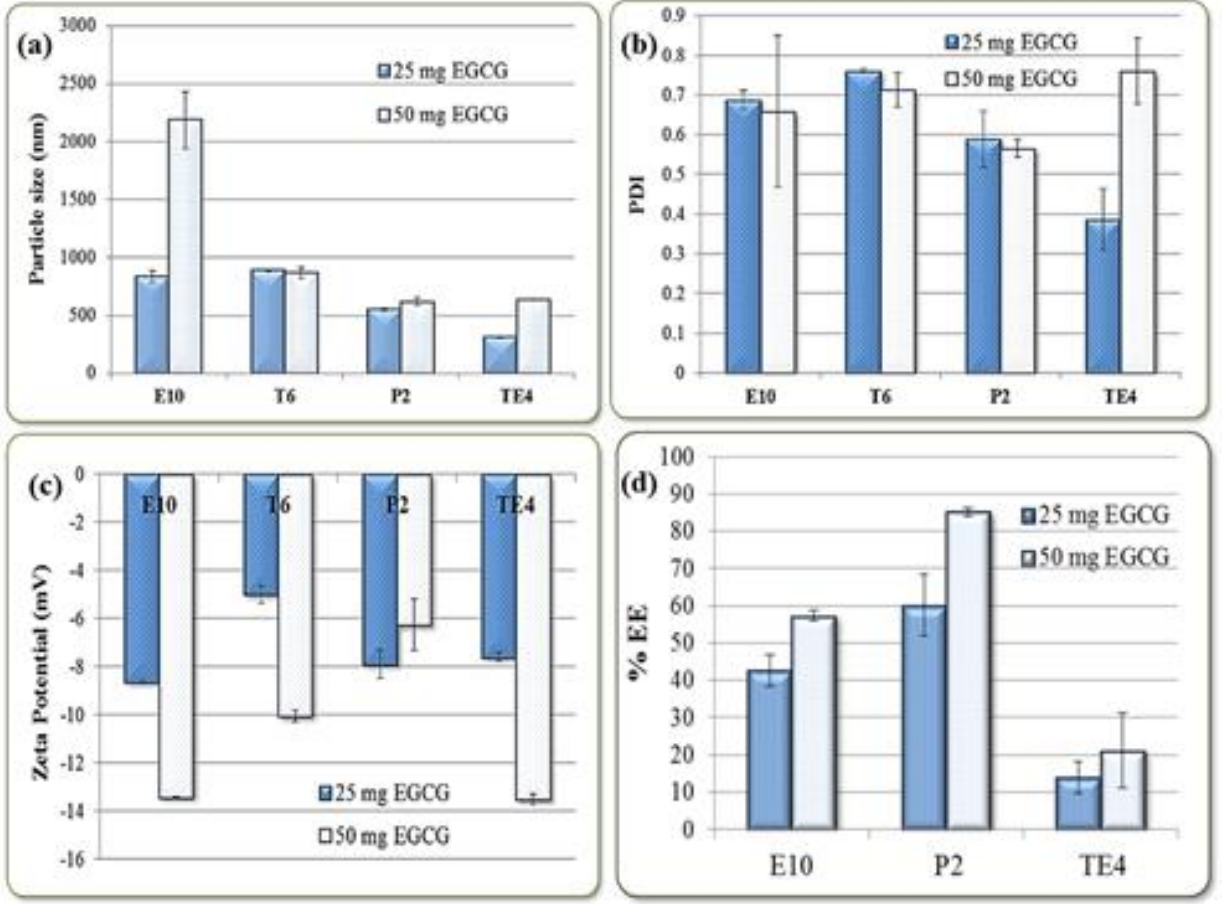

Figure 2.

Effect of varying EGCG loading dose on the particle size (a), PDI (b), zeta potential (c) and \%EE (d) of different vesicular systems

As clearly observed, reducing EGCG loading dose in the different vesicular systems decreased their particle size to different extents. The decrease in particle size was significant in EthOH-containing formulae; ethosomes $(\mathrm{p}<0.001)$ and TEs $(\mathrm{p}<0.01)$, however it was insignificant in case of transfersomes and PEVs ( $p>$ $0.05)$. The increase in particle size with increasing the loading dose might be ascribed to the fact that EGCG is entrapped in the lipid bilayer of the vesicles, consequently, increasing EGCG loading dose might increase the amount entrapped in the bilayer, thus increasing vesicle size. This is attributed to EGCG conformational structure, being a cis-type catechin, according to configuration of the two hydrogen atoms at the 2 position on the C-ring [57], as well as its hydrophobicity which favours its loading within the vesicles leading to increased particle size [44].

Upon decreasing the dose of EGCG from 50 to $25 \mathrm{mg}$, the value of PDI was nearly unchanged in all the prepared vesicular systems ( $p>0.05$ ) except for TEs. Regarding zeta potential, decreasing EGCG dose from 50 to $25 \mathrm{mg}$ significantly decreased the zeta potential of all the prepared vesicles ( $p<0.05)$, except for PEVs where it was insignificantly changed $(p>0.05)$. Based on the obtained results of zeta potential, EGCG was believed to be the source of negative charge, where as its concentration was increased in the formulation, the charge on the vesicles increased.

Effect of EGCG loading dose on the entrapment efficiency of vesicular systems. Encapsulation efficiency $(\% \mathrm{EE})$ is one of the important parameters in the design of vesicular formulations as drug carriers. High encapsulation efficiency ensures more bioavailability and also high concentration of targeted drug, that may help in the reduction of dose required for therapy and thereby decrease the dose related systemic side effects $[20,88]$. Thereby the \%EE of EGCG upon loading vesicles with $50 \mathrm{mg}$ and $25 \mathrm{mg}$ of EGCG was determined and presented as percentages of total loading dose (Figure 2).

During the optimization trials, it was observed that transfersomes exhibited large particle size, wide size distribution and low zeta potential, while better physicochemical properties were obtained on preparing TEs thus; transfersomes were excluded from further study, since our aim was to enhance the topical delivery efficacy of EGCG via nanovesicles exhibiting lowest particle size, concurring with other authors $[51,105]$. 
When $50 \mathrm{mg}$ EGCG were loaded in the vesicles, the values of \%EE in PEVs, ethosomes and TEs was $85.11 \%, 57.28 \%$ and $21.19 \%$, respectively. When EGCG dose was reduced to $25 \mathrm{mg}$, the values of $\%$ EE significantly decreased to $60 \%$ and $42.7 \%$ for PEVs and ethosomes, respectively $(\mathrm{p}<0.05)$ and insignificantly decreased to $14 \%$ for TEs $(p>0.05)$.

As a general observation, the highest \%EE values were observed with PEVs followed by ethosomes and finally TEs. The significantly higher $\% \mathrm{EE}$ values of PEVs may be attributed to the presence of PEG 400 which has a hydrophilic and a hydrophobic region that facilitate the entrapment of lipophilic drugs [26]. Moreover, high \%EE of PEVs can also be correlated with the significantly larger particle size of formula P2"enabling them to entrap more drug [87]. The lower values of \%EE exhibited by ethosomes and TEs could be attributed to the presence of EthOH which is believed to render the membrane of EthOH-containing vesicles leaky to the drug as previously deduced [15, 83].

The extensive reduction of the \%EE observed with transethosomes can be justified based on the synergistic effect of $\mathrm{Tw}_{80}$ and EthOH in increasing vesicles leakage. Ethanol was previously reported to cause the vesicle bilayer to be leaky that can lead to decrease in \%EE [3]. Van den Bergh et al. [104], Mishra et al. [70] and Bnyan et al. [19] previously reported that the incorporation of surfactants in vesicle formulation may lead to pore generation of the PL bilayers of the vesicles. This may be due to the fact that surfactant molecule gets associated with the PL bilayer, disrupting the lipid membrane with better partitioning of the drug thus the lipid membrane becomes leaky to the entrapped drug [37]. This is contrary to other published data where surfactants were found to increase the encapsulation of drugs either by direct solubilisation in the solid-lipid nanoparticles or through stabilization of the formed particles and hence preventing drug leakage $[2,71]$.

The decrease in the values of \%EE observed with decreasing EGCG loading dose in PEVs, transfersomes and TEs was in consistence with the previous finding of particle size and zeta potential (as the EGCG loading dose was decreased from 50 to $25 \mathrm{mg}$, the size as well as zeta potential of the prepared vesicles decreased significantly). The obtained results were in agreement with the findings reported by Fang et al. [44] that EGCG strongly locates itself within bilayers. In other words increasing the loading dose increased the amount of EGCG entrapped in the vesicle bilayer, thus increasing vesicles' size and zeta potential.

Optimization of the colloidal properties of EGCGloaded vesicular systems

In an attempt to achieve both high drug loading and good colloidal properties, another approach was attempted to reduce the particle size of the vesicles loaded with $50 \mathrm{mg}$ EGCG (P2", E10" and TE4") since they showed high \%EE, through changing the volume of the organic solvent of PL dispersion during thin film formation as well as the volume of the film hydration medium. A volume of $20 \mathrm{~mL}$ organic solvent (methanol) was used for dissolving the components instead of $10 \mathrm{~mL}$ in the standard method. The hydration of the thin film formed after evaporation was carried out using $20 \mathrm{~mL}$ of water/permeation enhancer mixture in PEVs or $20 \mathrm{~mL}$ hydroalcoholic solution in ethosomes and TEs instead of the $10 \mathrm{~mL}$ applied in the standard method. The colloidal parameters were measured after varying the volume of both media in systematic manner and results were compared (Figure 3).

It was observed that upon doubling the volume of organic solvent $(20 \mathrm{O} / 10 \mathrm{~A})$ in ethosomes (formula E10") and PEVs (formula P2") at standard volume $(10 \mathrm{~mL})$ of hydration medium, the particle size was significantly reduced $(\mathrm{p}<0.05)$. Doubling the volume of hydration medium at standard organic solvent volume $(10 \mathrm{O} / 20 \mathrm{~A})$ significantly reduced the particle size of PEVs (P2"), ethosomes (E10") and TEs (TE4") $(\mathrm{p}<0.05)$. Increasing the volumes of both organic solvent and hydration medium (200/20A) significantly reduced particle size of EthOH-containing vesicles (E10" and TE4") ( $\mathrm{p}<0.05)$.

The marked decrease in the particle size of ethosomes and PEVs upon increasing the volume of organic solvent (at $10 \mathrm{~mL}$ hydration medium) could be ascribed to the production of thinner film with homogenously dispersed components (PL and EGCG) in the $20 \mathrm{~mL}$ organic solvent, that led to the reduction of the vesicle size. This came in accordance with the results reported by Edgerly-Plug [36] while investigating the control of liposomes size through varying the volume of organic solvent. On the other hand, the significant decrease in vesicle particle size upon increasing the volume of hydration medium can be explained on the basis of the ample space provided for vesicle formation upon doubling the volume of the hydration media to $20 \mathrm{~mL}$ that reduces the probability of particles coalescence during vesicle formation, producing small particles. The lower volume $(10 \mathrm{~mL})$ may have led to incomplete or distorted formation of bilayer due to excess material and low space as a result of low hydration. Furthermore, the reduced viscosity of the hydrated dispersion could assist more effective size reduction during sonication. Similar results were previously reported by Sankhyan et al. [91] while preparing metformin-loaded niosomes.

Regarding PDI values of the prepared vesicles, a positive correlation could be inferred between the particle size and PDI, in which an increase in particle size was accompanied by an increase in PDI values. As illustrated (Figure 3), a significant change was observed in the zeta potential values upon increasing the aqueous phase volume at low organic phase volume of $10 \mathrm{~mL}(\mathrm{p}<0.05)$ in all systems except PEVs which was insignificant $(\mathrm{p}>0.05)$. 

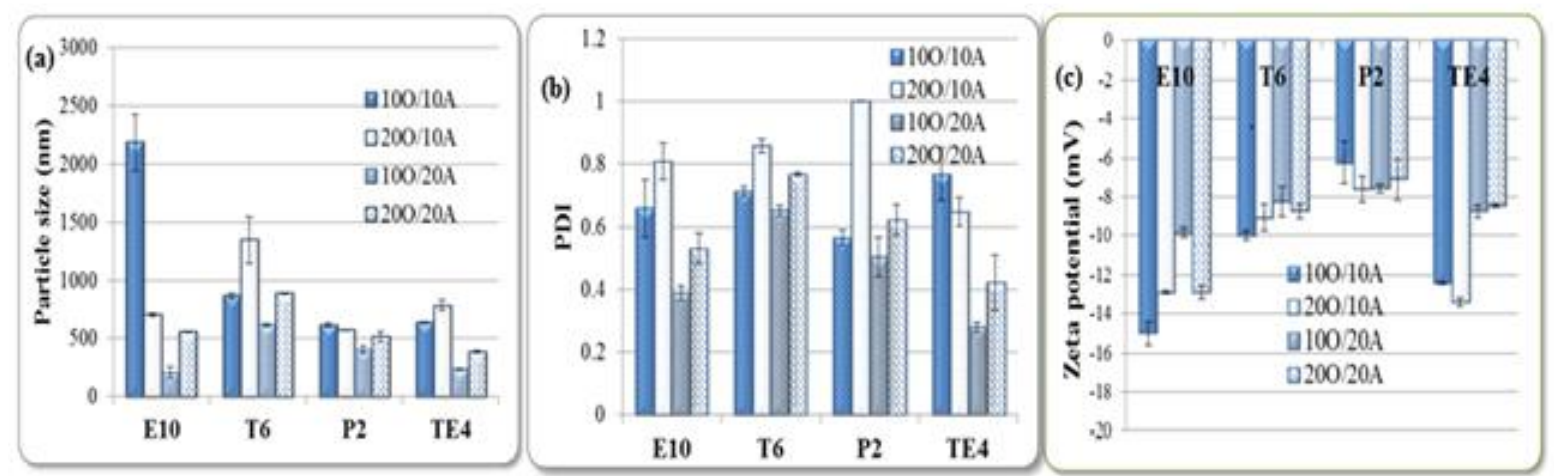

Figure 3.

Effect of changing the volume of organic solvent and hydration medium on the particle size (a), PDI (b) and zeta potential (c) of selected vesicular systems loaded with $50 \mathrm{mg}$ EGCG

Upon the determination of the \%EE (Table V) it was clear that, doubling the volume of the hydration medium (at $10 \mathrm{~mL}$ organic solvent volume) significantly increased the \%EE of EGCG in EthOH-containing vesicles (E10" and TE4") ( $\mathrm{p}<0.05)$. However, an insignificant effect was observed with the PEVs (P2") $(p>0.05)$ under the same condition. In general, it was observed that EGCG was adequately encapsulated in the optimized vesicles (ranging from $57.46 \%$ to $83.45 \%$ ), owing to its lipophilicity as its $\log \mathrm{P}$ value was reported to be $1.35 \pm 0.07[49,56]$.

Table V

Effect of organic solvent and/or hydration media volumes on $\% \mathrm{EE}($ mean $\pm \mathrm{SD}, \mathrm{n}=3)$

\begin{tabular}{|c|c|c|}
\hline \multicolumn{2}{|c|}{ Formulae Code } & $\% \mathrm{EE}$ \\
\hline \multirow{4}{*}{ Ethosomes } & E10"(10/10) & $57.281 \pm 1.363$ \\
\hline & E10”(20/10) & $52.736 \pm 0.989$ \\
\hline & E10”(10/20) & $74.682 \pm 1.107$ \\
\hline & E10”(20/20) & $65.610 \pm 1.055$ \\
\hline \multirow{4}{*}{ PEVs } & P2"(10/10) & $85.109 \pm 1.078$ \\
\hline & P2"(20/10) & $77.422 \pm 2.861$ \\
\hline & P2"(10/20) & $83.449 \pm 0.625$ \\
\hline & P2"(20/20) & $83.048 \pm 0.142$ \\
\hline \multirow{4}{*}{ TEs } & TE4"(10/10) & $21.198 \pm 1.879$ \\
\hline & TE4"(20/10) & $27.871 \pm 3.803$ \\
\hline & TE4"'(10/20) & $57.458 \pm 1.113$ \\
\hline & TE4"'(20/20) & $58.809 \pm 1.085$ \\
\hline
\end{tabular}

\section{Conclusions}

The nature and the ratio of various excipients applied in vesicles formulation exhibited major effects on their colloidal properties. Therefore, optimization of formulation composition was essential in order to produce vesicles with acceptable physical properties. It was generally observed that particle size and size distribution of vesicular systems decreased as the permeation enhancer concentration were increased and PL amount was decreased. The incorporation of EGCG into different vesicles increased particle size, PDI values and surface charge of the vesicular systems. Reduction of particle size and PDI after drug loading could be achieved by increasing the volume of the organic solvent used as a dispersion medium during vesicles preparation and to a higher extent with increasing the volume of the hydration medium followed by sonication.

\section{Acknowledgement}

The authors would like to thank Cargill Company, Germany for their kind supply of Epikuron 200.

\section{Conflict of interest}

The authors declare no conflict of interest.

\section{References}

1. Abdelgawad R, Nasr M, Moftah NH, Hamza MY, Phospholipid membrane tubulation using ceramide doping "Cerosomes": characterization and clinical application in psoriasis treatment. Eur J Pharm Sci., 2017; 101: 258-268.

2. Abdel-Salam FS, Mahmoud AA, Ammar HO, Elkheshen SA, Nanostructured lipid carriers as semisolid topical delivery formulations for diflucortolone valerate. $J$ Liposome Res., 2017; 27(1): 41-55.

3. Abdulbaqi IM, Darwis Y, Khan NAK, Assi RA, Khan AA, Ethosomal nanocarriers: the impact of constituents and formulation techniques on ethosomal properties, in vivo studies, and clinical trials. Int J Nanomed., 2016; 11: 2279-2304.

4. Agiba AM, Nasr M, Abdel-Hamid S, Eldin AB, Geneidi AS, Enhancing the intestinal permeation of the chondroprotective nutraceuticals glucosamine sulphate and chondroitin sulphate using conventional and modified liposomes. Curr Drug Deliv., 2018; 15(6): 907-916.

5. Akbarzadeh A, Rezaei-Sadabady R, Davaran S, Joo SW, Zarghami N, Hanifehpour Y, Samiei M, Kouhi M, Nejati-Koshki K, Liposome: classification, preparation, and applications. Nanoscale Res Lett., 2013; 8(1): 102.

6. Antonietti M, Förster S, Vesicles and liposomes: a self-assembly principle beyond lipids. Adv Mater., 2003; 15: 1323-1333.

7. Arafa MG, Ayoub BM, Bioavailability study of niosomal salbutamol sulfate in metered dose inhaler: controlled pulmonary drug delivery. J Aerosol Med Pulm Drug Deliv., 2018; 31(2): 114-115. 
8. Arafa MG, Ayoub BM, DOE optimization of nanobased carrier of pregabalin as hydrogel: new therapeutic and chemometric approaches for controlled drug delivery systems. Sci Rep., 2017; 7: 41503.

9. Aref NEM, Nasr M, Osman R, Novel heat-stable enterotoxin (STa) immunogen based on cationic nanoliposomes: Preparation, characterization and immunization. J Vaccines Vaccin., 2017; 8(1): 1-8.

10. Asasutjarit R, Sorrachaitawatwong C, Tipchuwong N, Pouthai S, Effect of formulation compositions on particle size and zeta potential of diclofenac sodiumloaded chitosan nanoparticles. Int J Medic Health Biomedic Bioengin Pharmaceut Engin., 2013; 7(9): 568-570.

11. Ascenso A, Raposo S, Batista C, Cardoso P, Mendes T, Praça FG, Bentley MV, Simões S, Development, characterization, and skin delivery studies of related ultradeformable vesicles: transfersomes, ethosomes, and transethosomes. Int J Nanomed., 2015; 10: 5837-5851.

12. Ashraf O, Nasr M, Nebsen M, Said AMA, Sammour $\mathrm{O}$, In-vitro stabilization and in-vivo improvement of ocular pharmacokinetics of the multi-therapeutic agent baicalin: Delineating the most suitable vesicular systems. Int J Pharm., 2018; 539: 83-94.

13. Barakat SS, Nasr M, Ahmed RF, Badawy SS, Mansour $\mathrm{S}$, Intranasally administered in situ gelling nanocomposite system of dimenhydrinate: Preparation, characterization and pharmacodynamic applicability in chemotherapy induced emesis model. Sci Rep., 2017; 7(1): 9910.

14. Barakat SS, Nasr M, Badawy SS, Mansour S, Nanoliposomes containing penetration enhancers for the intranasal delivery of the antiemetic dimenhydrinate. IJPRBS., 2016; 5(1): 111-122.

15. Barupal AK, Gupta V, Ramteke S, Preparation and characterization of ethosomes for topical delivery of aceclofenac. Ind J Pharm Sci., 2010; 72(5): 582-586.

16. Barras A, Mezzetti A, Richard A, Lazzaroni S, Roux S, Melnyk P, Betbeder D, Monfilliette-Dupont N, Formulation and characterization of polyphenolloaded lipid nanocapsules. Int J Pharm., 2009; 379(2): 270-277.

17. Basha M, Abd El-Alim SH, Shamma RN, Awad GE, Design and optimization of surfactant-based nanovesicles for ocular delivery of Clotrimazole. $J$ Liposome Res., 2013; 23(3): 203-210.

18. Bhana R, Verma A, Jain S, Development and characterization of ethosomes bearing losartan potassium for transdermal drug delivery. Int J Pharm Pharm Sci., 2013; 5(1): 35-40.

19. Bnyan R, Khan I, Ehtezazi T, Saleem I, Gordon S, O'Neill F, Roberts M, Surfactant effects on lipidbased vesicles properties. J Pharm Sci., 2018; 107(5): 1237-1246.

20. Bozzuto G, Molinari A, Liposomes as nanomedical devices. Int J Nanomed., 2015; 10: 975-999.

21. Brand RM, Jendrzejewski JL, Topical treatment with (-)-epigallocatechin-3-gallate and genistein after a single UV exposure can reduce skin damage. J Dermatol Sci., 2008; 50: 69-72.

22. Bseiso EA, Nasr M, Sammour OA, Abd El Gawad NA, Novel nail penetration enhancer containing vesicles "nPEVs" for treatment of onychomycosis. Drug Deliv., 2016; 23(8): 2813-2819.
23. Bsieso EA, Nasr M, Moftah NH, Sammour OA, Abd El Gawad NA, Could nanovesicles containing a penetration enhancer clinically improve the therapeutic outcome in skin fungal diseases?. Nanomed. (Lond), 2015; 10(13): 2017-2031.

24. Budai M, Chapela P, Budai L, Wales ME, Petrikovics I, Zimmer A, Gróf P, Klebovich I, Szilasi M, Liposomal oxytetracycline and doxycycline: studies on enhancement of encapsulation efficiency. Drug Discov Ther., 2009; 3(1): 13-17.

25. Buzea C, Pacheco II, Robbie K, Nanomaterials and nanoparticles: Sources and toxicity. Biointerphases, 2007; 2(4): MR17-MR71.

26. Caddeo C, Díez-Sales O, Pons R, Fernàndez-Busquets X, Fadda AM, Manconi M, Topical anti-inflammatory potential of quercetin in lipid-based nanosystems: in vivo and in vitro evaluation. Pharm Res., 2014; 31(4): 959-968.

27. Cevc G, Blume G, New, highly efficient formulation of diclofenac for the topical, transdermal administration in ultradeformable drug carriers, Transfersomes. BBA-Biomembranes, 2001; 1514(2): 191-205.

28. Chen $X Q$, Wang $X B$, Guan RF, Tu J, Gong ZH, Zheng N, Yang JH, Zhang YY, Ying MM, Blood anticoagulation and antiplatelet activity of green tea (-)-epigallocatechin (EGC) in mice. Food Funct., 2013; 4(10): 1521-1525.

29. Connors KA, Amidon GL, Stella VJ, In: Chemical stability of pharmaceuticals: a handbook for pharmacists, John Wiley \& Suns, $2^{\text {nd }}$ Ed., 1986; Chapter 4.

30. Dave V, Kumar D, Lewis S, Paliwal S, Ethosome for enhanced transdermal drug delivery of aceclofenac. IJDD., 2010; 2(1): 81-92.

31. Danciu C, Pinzaru IA, Dehelean CA, Hancianu M, Zupko I, Navolan D, Licker M, Ghiulai RM, Şoica $\mathrm{CM}$, Antiproliferative and antimicrobial properties of pure and encapsulated rutin. Farmacia, 2018; 66(2): 302-308.

32. Dua JS, Rana AC, Bhandari AK, Liposome: methods of preparation and applications. Int J Pharm Stud Res. (IJPSR), 2012; 3(2): 14-20.

33. Duangjit $S$, Opanasopit $P$, Rojanarata T, Ngawhirunpat T, Evaluation of meloxicam-loaded cationic transfersomes as transdermal drug delivery carriers. AAPS Pharm SciTech., 2013; 14(1): 133-140.

34. Duangit S, Opanasopit P, Rojanarata T, Ngawhirunpat T, Characterization and in-vitro skin permeation of meloxicam-loaded liposomes versus transfersomes. J Drug Deliv., 2010; 2011: 1-9.

35. Dube A, Nicolazzo JA, Larson I, Chitosan nanoparticles enhance the intestinal absorption of the green tea catechins (+)-catechin and (-)-epigallocatechin gallate. Eur J Pharm Sci., 2010; 41(2): 219-225.

36. Edgerly-Plug LM, Elan Pharmaceuticals LLC. Method of controlling the size of liposomes, 2003; U.S. Patent $6,596,305$.

37. Edwards K, Almgren M, Kinetics of surfactantinduced leakage and growth of unilamellar vesicles. Surfactants and Macromolecules: Self-Assembly at Interfaces and in Bulk, 1990; 82: 190-197.

38. El-Kayal MO, Sayed MN, Mortada ND, Elkheshen S, Development and validation of a simple and rapid UPLC method for the in-vitro estimation of (-)- 
epigallocatechin-3-gallate in lipid-based formulations. Eur J Chem., 2018; 9 (1): 7-12.

39. El Maghraby GM, Barry BW, Williams AC, Liposomes and skin: from drug delivery to model membranes. Eur J Pharm Sci., 2008; 34(4): 203-222.

40. Elsayed MMA, Abdallah OY, Naggar VF, Khalafallah NM, Lipid vesicles for skin delivery of drugs: reviewing three decades of research. Int J Pharm., 2007; 332(1): 1-16.

41. El Zaafarany GM, Awad GAS, Holayel SM, Mortada $\mathrm{ND}$, Role of edge activators and surface charge in developing ultradeformable vesicles with enhanced skin delivery. Int J Pharm., 2010; 397(1): 164-172.

42. Fadel M, Samy N, Nasr M, Alyoussef AA, Topical colloidal indocyanine green-mediated photodynamic therapy for treatment of basal cell carcinoma. Pharm Dev Technol., 2017; 22(4): 545-550.

43. Fang JY, Hung CF, Hwang TL, Huang YL, Physicochemical characteristics and In-vivo deposition of liposomeencapsulated tea catechins by topical and intratumor administrations. J Drug Target, 2005; 13(1): 19-27.

44. Fang JY, Hwang TL, Huang YL, Fang CL, Enhancement of the transdermal delivery of catechins by liposomes incorporating anionic surfactants and ethanol. Int $J$ Pharm., 2006; 310(1): 131-138.

45. Fangueiro JF, Parra A, Silva AM, Egea MA, Souto EB, Garcia ML, Calpena AC, Validation of a high performance liquid chromatography method for the stabilization of epigallocatechin gallate. Int J Pharm., 2014; 475(1): 181-190.

46. Garg V, Singh H, Bhatia A, Raza K, Singh SK, Singh B, Beg S, Systematic development of transethosomal gel system of piroxicam: formulation optimization, in vitro evaluation, and ex vivo assessment. AAPS PharmSciTech., 2017; 18(1): 58-71.

47. Ghanbarzadeh S, Valizadeh H, Zakeri-Milani P, Application of response surface methodology in development of sirolimus liposomes prepared by thin film hydration technique. BioImpacts: BI, 2013; 3(2): 75-81.

48. Granja A, Frias I, Neves AR, Pinheiro M, Reis S, Therapeutic potential of Epigallocatechin gallate nanodelivery systems. Biomed Res Int., 2017; 2017: $1-15$.

49. Hashimoto T, Kumazawa S, Nanjo F, Hara Y, Nakayama T, Interaction of tea catechins with lipid bilayers investigated with liposome systems. Biosci Biotechnol Biochem., 1999; 63(12): 2252-2255.

50. Hemanthkumar M, Spandana V, Liposomal encapsulation technology A novel drug delivery system designed for ayurvedic drug preparation. IRJP., 2011; 2(10): 4-6.

51. Hua S, Lipid-based nano-delivery systems for skin delivery of drugs and bioactives. Front Pharmacol., 2015; 6: 219.

52. Huang YB, Tsai MJ, Wu PC, Tsai YH, Wu YH, Fang $\mathrm{JU}$, Elastic liposomes as carriers for oral delivery and the brain distribution of (+)-catechin. J Drug Target, 2011; 19(8): 709-718.

53. Irfan $M$, Verma S, Ram A, Preparation and characterization of ibuprofen loaded transferosome as a novel carrier for transdermal drug delivery system. Asian J Pharm Clin Res., 2012; 5(3): 162-165.

54. Italia JL, Datta P, Ankola DD, Kumar MNV, Nanoparticles enhance per oral bioavailability of poorly available molecules: epigallocatechin gallate nanoparticles ameliorates cyclosporine induced nephrotoxicity in rats at three times lower dose than oral solution. $J$ Biomed Nanotech., 2008; 4(3): 304-312.

55. Jacob L, Anoop KR, A review on surfactants as edge activators in ultradeformable vesicles for enhanced skin delivery. Int J Pharma Bio Sci., 2013; 4(3): 337-344.

56. Kajiya K, Kumazawa S, Naito A, Nakayama T, Solidstate NMR analysis of the orientation and dynamics of epigallocatechin gallate, a green tea polyphenol, incorporated into lipid bilayers. Magn Reson Chem., 2008; 46(2): 174-177.

57. Kajiya K, Kumazawa S, Nakayama T, Steric effects on interaction of tea catechins with lipid bilayers. Biosci Biotech Biochem., 2001; 65(12): 2638-2643.

58. Karn PR, Cho W, Park HJ, Park JS, Hwang SJ, Characterization and stability studies of a novel liposomal cyclosporin A prepared using the supercritical fluid method: comparison with the modified conventional Bangham method. Int $J$ Nanomed., 2013; 8: 365-377.

59. Kõiv A, Kinnunen PKJ, Influence of $\mathrm{Ca}^{2+}$ and ethanol on the aggregation and thermal phase behaviour of Ldihexadecylphosphatidylcholine liposomes. Chem Phys Lipids, 1992; 62(3): 253-261.

60. Komatsu H, Okada S, Ethanol-induced aggregation and fusion of small phosphatidylcholine liposome: participation of interdigitated membrane formation in their processes. BBA-Biomembranes, 1995; 1235(2): 270-280.

61. Kumar GP, Rajeshwarrao P, Nonionic surfactant vesicular systems for effective drug delivery - an overview. Acta Pharmaceutica Sinica B, 2011; 1(4): 208-219.

62. Kushwaha AK, Vuddanda PR, Karunanidhi P, Singh SK, Singh S, Development and evaluation of solid lipid nanoparticles of raloxifene hydrochloride for enhanced bioavailability. Biomed Res Int., 2013; 2013: 1-9.

63. Labhasetwar V, Mohan M, Dorle A, A study on zeta potential and dielectric constant of liposomes. $J$ Microencaps., 1994; 11(6): 663-668.

64. Lei W, Yu C, Lin H, Zhou X, Development of tacrolimus-loaded transfersomes for deeper skin penetration enhancement and therapeutic effect improvement in-vivo. AJPS., 2013; 8(6): 336-345.

65. Liu X, Liu H, Liu J, He Z, Ding C, Huang G, Zhou W, Zhou L, Preparation of a ligustrazine ethosome patch and its evaluation in vitro and in vivo. Int J Nanomed., 2011; 6: 241-247.

66. Madhavi BB, Vennela KS, Masana P, Madipoju B, Enhanced transdermal drug penetration of curcumin via ethosomes. Malaysian J Pharmaceut Sci., 2013; 11(1): 48-58.

67. Manconi M, Sinico C, Caddeo C, Vila AO, Valenti D, Fadda AM, Penetration enhancer containing vesicles as carriers for dermal delivery of tretinoin. Int $J$ Pharm., 2011; 412: 37-46.

68. Manosroi A, Jantrawut P, Khositsuntiwong N, Manosroi W, Manosroi J, Novel Elastic Nanovesicles for Cosmeceutical and Pharmaceutical Applications. Chiang Mai J Sci., 2009; 36(2): 168-178. 
69. McIntosh TJ, Lin H, Li S, Huang CH, The effect of ethanol on the phase transition temperature and the phase structure of monounsaturated phosphatidylcholines. BBA Biomembranes, 2001; 1510(1): 219-230.

70. Mishra D, Garg M, Dubey V, Jain S, Jain NK, Elastic liposomes mediated transdermal delivery of an antihypertensive agent: Propranolol hydrochloride. $J$ Pharm Sci., 2007; 96(1): 145-155.

71. Mobarak DH, Salah S, Elkheshen SA, Formulation of ciprofloxacin hydrochloride loaded biodegradable nanoparticles: optimization of technique and process variables. Pharm Dev Tech., 2014; 19(7): 891-900.

72. Mut AM, Vlaia L, Coneac G, Olariu I, Vlaia V, Popoiu C, Hîrjău M, Lupuliasa D, Novel topical chitosan/hydroxypropylmethylcellulose - based hydrogels containing fluconazole and sucrose esters. Formulation, physicochemical characterization, in vitro drug release and permeation. Farmacia, 2018; 66(1): 59-69.

73. Mouez MA, Nasr M, Abdel-Mottaleb M, Geneidi AS, Mansour S, Composite chitosan-transfersomal vesicles for improved transnasal permeation and bioavailability of verapamil. Int J Biol Macromol., 2016; 93: 591-599.

74. Mukherjee B, Patra B, Layek B, Mukherjee A, Sustained release of acyclovir from nano-liposomes and nanoniosomes: an in-vitro study. Int J Nanomed., 2007; 2(2): 213-225.

75. Mura S, Manconi M, Fadda AM, Sala MC, Perricci J, Pini E, Sinico C, Penetration enhancer-containing vesicles (PEVs) as carriers for cutaneous delivery of minoxidil: in vitro evaluation of drug permeation by infrared spectroscopy. Pharm Dev Tech., 2013; 18(6): 1339-1345.

76. Nandure HP, Puranik P, Giram P, Lone V, Ethosome: A Novel Drug Carrier. IJPRAS., 2013; 2(3): 18-30.

77. Narayanan K, Subrahmanyam VM, Venkata Rao J, A fractional factorial design to study the effect of process variables on the preparation of hyaluronidase loaded PLGA nanoparticles. Enzyme Res., 2014; 2014: $1-10$

78. Nascimento DB, Rapuano R, Lessa MM, CarmonaRibeiro AM, Counterion effects on properties of cationic vesicles. Langmuir, 1998; 14(26): 7387-7391.

79. Nasr M, Mansour S, Mortada ND, Elshamy AA, Vesicular Aceclofenac systems: A comparative study between liposomes and niosomes. J Microencapsul., 2008; 25(7): 499-512.

80. Nasr M, Taha I, Hathout RM, Suitability of liposomal carriers for systemic delivery of risedronate using the pulmonary route. Drug Deliv., 2013; 20(8): 311-318.

81. Nava G, Piñón E, Mendoza L, Mendoza N, Quintanar $\mathrm{D}$, Ganem A, Formulation and in Vitro, ex Vivo and in Vivo evaluation of elastic liposomes for transdermal delivery of ketorolac tromethamine. Pharmaceutics, 2011; 3(4): 954-970.

82. Niu M, Lu Y, Hovgaard L, Wu W, Liposomes containing glycocholate as potential oral insulin delivery systems: preparation, in vitro characterization and improved protection against enzymatic degradation. Int J Nanomed., 2011; 6: 1155-1166.

83. Patel RB, Parikh RH, Preparation and formulation of transferosomes containing an antifungal agent for transdermal delivery: Application of Plackett-Burman design to identify significant factors influencing vesicle size. J Pharm Bioallied Sci., 2012; 4(Suppl 1): 60-61.

84. Polozova A, Li X, Shangguan T, Meers P, Schuette DR, Ando N, Gruner SM, Perkins WR, Formation of homogeneous unilamellar liposomes from an interdigitated matrix. BBA Biomembranes, 2005; 1668(1): 117-125.

85. Prasanthi D, Lakshmi PK, Statistically optimised ethosomes for transdermal delivery of tolterodine tartrate. Pak J Pharm Sci., 2013; 26(6): 1117-1122.

86. Rakesh R, Anoop K, Formulation and optimization of nano-sized ethosomes for enhanced transdermal delivery of cromolyn sodium. J Pharm Bioallied Sci., 2012; 4(4): 333-340.

87. Ramana LN, Sethuraman S, Ranga U, Krishnan UM, Development of a liposomal nanodelivery system for nevirapine. J Biomed Sci., 2010; 17(1): 57.

88. Rangasamy M, Ayyasamy B, Raju S, Gummadevelly $\mathrm{S}$, Shaik S, Formulation and in vitro evaluation of niosome encapsulated acyclovir. J Pharm Res., 2008; 1(2): 163-166.

89. Roge AB, Sakhare RS, Bakal RL, Channawar MA, Bakade BV, Gawande SR, Chandewar AV, Ethosomes: Novel Approach in Transdermal Drug Delivery System. RJPDFT., 2010; 2(1): 23-27.

90. Samad A, Sultana Y, Aqil M, Liposomal drug delivery systems: an update review. Curr Drug Deliv., 2007; 4(4): 297-305.

91. Sankhyan A, Pawar PK, Metformin loaded non-ionic surfactant vesicles: optimization of formulation, effect of process variables and characterization. $D A R U$ J Pharm Sci., 2013; 21(1): 1-8.

92. Santagati NA, Salerno L, Attaguile G, Savoca F, Ronsisvalle G, Simultaneous determination of catechins, rutin, and gallic acid in Cistus species extracts by HPLC with diode array detection. J Chromatogr Sci., 2008; 46(2): 150-156.

93. Shaker S, Gardouh AR, Ghorab MM, Factors affecting liposomes particle size prepared by ethanol injection method. Res Pharm Sci., 2017; 12(5): 346-352.

94. Shamma RN, Elsayed I, Transfersomal lyophilized gel of buspirone $\mathrm{HCl}$ : formulation, evaluation and statistical optimization. J Liposome Res., 2013; 23(3): 244-254.

95. Shutava TG, Balkundi SS, Vangala P, Steffan JJ, Bigelow RL, Cardelli JA, O'Neal DP, Lvov YM, Layer-by-Layer-coated gelatin nanoparticles as a vehicle for delivery of natural polyphenols. ACS Nano, 2009; 3(7): 1877-1885.

96. Siddiqui IA, Adhami VM, Bharali DJ, Hafeez BB, Asim M, Khwaja SI, Ahmad N, Cui H, Mousa SA, Mukhtar H, Introducing nanochemoprevention as a novel approach for cancer control: proof of principle with green tea polyphenol epigallocatechin-3-gallate. Cancer Res., 2009; 69(5): 1712-1716.

97. Singh SK, Dadhania P, Vuddanda PR, Jain A, Velaga $S$, Singh S, Intranasal delivery of asenapine loaded nanostructured lipid carriers: formulation, characterization, pharmacokinetic and behavioural assessment. RSC Advances, 2016; 6(3): 2032-2045.

98. Spuch C, Navarro C, Liposomes for Targeted Delivery of Active Agents against Neurodegenerative Diseases (Alzheimer's Disease and Parkinson's Disease). $J$ Drug Deliv., 2011; 2011: 1-12. 
99. Srikanth K, Gupta VRM, Devanna N, Ethanolic vesicles of nystatin for enhanced transdermal drug delivery: in-vitro and ex-vivo evaluation. Indo Am J Pharm Res., 2013; 3(9): 7316-7324.

100. Subongkot T; Pamornpathomkul B; Rojanarata T; Opanasopit P, Ngawhirunpat T, Investigation of the mechanism of enhanced skin penetration by ultradeformable liposomes. Int J Nanomed., 2014; 9: 3539-3550.

101. Sun Y, Hung WC, Chen FY, Lee CC, Huang HW, Interaction of Tea Catechin (-)-Epigallocatechin Gallate with Lipid Bilayers. Biophys J., 2009; 96(3): 1026-1035.

102. Touitou E, Dayan, N, Bergelson L, Godin B, Eliaz M, Ethosomes - novel vesicular carriers for enhanced delivery: characterization and skin penetration properties. J Control Release, 2000; 65(3): 403-418.

103. Tyagi LK, Kumar S, Maurya SS, Kori ML, Ethosomes: Novel vesicular carrier for enhanced transdermal drug delivery system. Bull Pharm Res., 2013; 3(1): 6-13.

104. Van den Bergh BAI, Wertz PW, Junginger HE, Bouwstra JA, Elasticity of vesicles assessed by electron spin resonance, electron microscopy and extrusion measurements. Int J Pharm., 2001; 217(1): 13-24.

105. Verma DD, Verma S, Blume G, Fahr A, Particle size of liposomes influences dermal delivery of substances into skin. Int J Pharm., 2003; 258(1-2): 141-151.

106. Verma P, Pathak K, Therapeutic and cosmeceutical potential of ethosomes: An overview. J Adv Pharm Technol Res., 2010; 1(3): 274-282.

107. Vijayakumar MR, Sathali AH, Arun K, Formulation and evaluation of diclofenac potassium ethosomes. Int J Pharm Pharm Sci., 2010; 2(4): 82-86.

108. Vuddanda PR, Mishra A, Singh SK, Singh S, Development of polymeric nanoparticles with highly entrapped herbal hydrophilic drug using nanoprecipitation technique: an approach of quality by design. Pharm Dev Tech., 2015; 20(5): 579-587.
109. Wang AZ, Gu F, Zhang L, Chan JM, RadovicMoreno A, Shaikh MR, Langer RS, Farokhzad OC, Biofunctionalized targeted nanoparticles for therapeutic applications. Exp Opin Biol Ther., 2008; 8(8): 1063-1070.

110. Więcek AE, Effect of phospholipid and (phospho) lipase modification on interfacial properties of oil/ water emulsion. Annales UMCS, Chemia, 2015; 70(1): 79-109.

111. Wijesooriya C, Budai M, Budai L, Szilasi ME, Petrikovics I, Optimization of liposomal encapsulation for ceftazidime for developing a potential eye drop formulation. J Basic Clin Pharm., 2013; 4(3): 73-75.

112. Wilson B, Samanta MK, Santhi K, Kumar KPS, Paramakrishnan N, Suresh B, Poly (n-butylcyano acrylate) nanoparticles coated with polysorbate 80 for the targeted delivery of rivastigmine into the brain to treat Alzheimer's disease. Brain Res., 2008; 1200: $159-168$.

113. Xu H, Deng YH, Wang KQ, Chen DW, Preparation and characterization of stable $\mathrm{pH}$-sensitive vesicles composed of $\alpha$-tocopherol hemisuccinate. AAPS PharmSciTech., 2012; 13(4): 1377-1385.

114. Yang CS, Lambert JD, Sang S, Antioxidative and anti-carcinogenic activities of tea polyphenols. Arch Toxicol., 2009; 83(1): 11-21.

115. Zhang L, Gu F, Chan JM, Wang AZ, Langer RS, Farokhzad OC, Nanoparticles in medicine: Therapeutic applications and developments. Clin Pharmacol Ther., 2008; 83(5): 761-769.

116. Zhao Y, Wang Z, Zhang W, Jiang X, Adsorbed Tween 80 is unique in its ability to improve the stability of gold nanoparticles in solutions of biomolecules. Nanoscale, 2010; 2(10): 2114-2119.

117. Zhaowu Z, Xiaoli W, Yangde Z, Nianfeng L, Preparation of matrine ethosome, its percutaneous permeation in vitro and anti-inflammatory activity in vivo in rats. J Liposome Res., 2009; 19(2): 155-162. 